\title{
A CASE OF HARTNUP DISEASE
}

\author{
BY \\ WALTER HENDERSON \\ From the County Hospital, York
}

(RECEIVED FOR PUBLICATION AUGUST 13, 1957)

This new disease was first described last year by Dr. Hart and Professor Dent and their colleagues (Baron, Dent, Harris, Hart and Jepson, 1956) under the title 'Hereditary pellagra-like skin rash with temporary cerebellar ataxia, constant aminoaciduria, and other bizarre biochemical features'.

The name 'Hartnup disease'-after the family then described-was later used in a reference to the syndrome by Harris (1957) and is that at present preferred by the original authors. No further accounts of cases have yet been published in this country and it seemed, therefore, that the following case was worthy of record. A brief reference to two further cases in Holland has been made by Jonxis (1957).

Angela P. was born on July 1, 1947, the second child of healthy, unrelated parents. Her infancy and early childhood were uneventful; she had most of the childhood infectious fevers but otherwise was well and grew normally. In March of 1952 she developed diarrhoea which was treated with a sulphonamide but did not clear up for nearly three weeks.

She was first seen in consultation on May 13, 1952, at the age of 4 years 10 months, on account of recurring attacks of unsteadiness, in some of which she fell and hurt herself. These episodes started shortly after the diarrhoea had cleared up. At about the same time she began to develop a rash on the face and lower parts of the arms. This rash was always made worse by exposure to the sun; it had been diagnosed as sensitivity to sunlight and was being treated with only partial success by protective creams. Her appetite was poor and she was rather temperamental. Apart from a mild ataxia there was little to be found abnormal in the nervous system.

When seen again six weeks later it was clear that there had been some deterioration: she was now unsteady at all times when on her feet, sometimes she felt giddy when walking about and would then sit down if possible; at other times she fell-rather more often to the left than to the right. The rash was as bad as ever and caused her a good deal of inconvenience. These troubles were making her more temperamental and difficult at home. She was admitted to hospital for five days on July 2 1952.

The clinical examination showed a girl of average physique, definitely ataxic whenever she walked. When walking about the ward she would sometimes appear to feel giddy or unsteady and would quickly sit down, but it was clear that she was constantly ataxic. The legs showed no wasting and the tendon reflexes were all slightly exaggerated. The plantar reflexes were flexor. The arms showed definite but mild intention tremor with increased tendon reflexes, but she could feed herself, play with toys and fasten buttons. No sensory disturbance could be made out. There was no papilloedema and no affection of any of the cranial nerves. A radiograph of the skull was normal. The urine showed no abnormalities.

The rash was quite striking, being only on the exposed areas of the body, and was very marked on the back of the neck, most of the face, the backs of the hands and outer surfaces of the arms-strictly to the sleeve leveland the dorsal surface of the feet where exposed through the straps of the sandals, the calves and knees to the lower limit of the dress. The skin in the affected areas was reddened, rough and dry; in a few areas it was thickened. Round the mouth and external nares there was hardening and cracking at the muco-cutaneous junctions.

The child was fretful during her stay, unhappy and anxious to get home. She did not vomit, her appetite was indifferent and she had no headache. No definite diagnosis was reached and she was allowed home.

When she was followed up six weeks later in the middle of August, it was reported that her unsteadiness was much more marked; she could only walk for a few yards and now moved about very little, being especially diffident about going up or downstairs.

Examination showed a more marked ataxia with very unsteady gait; she walked with a rather wide base and could only manage a few steps without support. The deep reflexes were still exaggerated. The arm and hand movements were jerky, there was intention tremor and she could feed herself only with considerable difficulty. The ocular fundi were normal. There was mild nystagmus, not very well sustained, detectable in both lateral directions. Her speech was rather slow and at times she tended to split up words. The rash was slightly more marked. She also had an angular stomatitis, a very slight atrophic glossitis, and a mild vulvitis. The hair was soft and loose, coming out readily when brushed and combed.

In view of the increasing severity of her symptoms she was transferred to The Hospital for Sick Children, Great 
Ormond Street, on August 27, 1952, under the care of Dr. P. R. Evans.

Investigation there confirmed the above findings, and the photographs (Fig. 1) show clearly the distribution of the rash. The cerebrospinal fluid was clear and contained no cells; protein was $30 \mathrm{mg}$. per $100 \mathrm{ml}$.; sugar, $91 \mathrm{mg} . / 100 \mathrm{ml}$.; chlorides, $700 \mathrm{mg} . / 100 \mathrm{ml}$.; and W.R. negative. The urine showed no porphyrins, but there was an increase in the amino-acid content.

Dr. Evans noted that the dermatitis in its appearance and distribution closely resembled that seen in pellagra and suggested that the other symptoms might also be due to vitamin B deficiency.

Treatment was therefore started on September 2 with riboflavin, $3 \mathrm{mg}$. t.d.s., and nicotinamide, $10 \mathrm{mg}$. four times daily, by mouth. She was given a high-protein diet, with added brewers' yeast. The skin was treated with cremor calamine.

Within a week of starting specific treatment it could be seen that the ataxia was less marked and the skin lesion definitely improving. After two weeks, improvement had reached the stage where she could walk without support. The deep reflexes were still brisk. She could

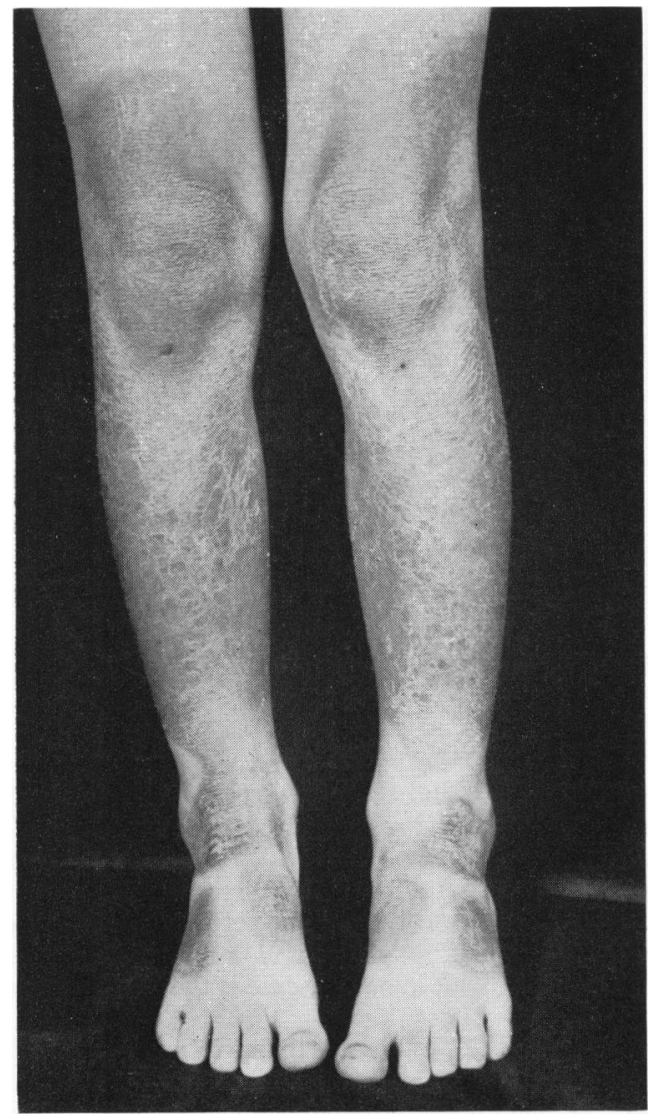

now feed herself much more readily. After four weeks, a test dose of ultra-violet light still showed some skin sensitivity.

After eight weeks' treatment she had gained $4 \mathrm{lb}$. in weight. She had apparently quite recovered and was allowed home on October 25, 1952, with instructions to take riboflavine and nicotinamide for a further three months.

A few months later she was reported to be perfectly well, attending school regularly and showing no behaviour difficulties.

Further retrospective enquiry into possible causes of the 'pellagra' syndrome suggested that her diet might have been partly to blame, as she had, for some months before her symptoms developed, lived largely on cornflakes and milk. There seemed to have been an association in time between the attack of diarrhoea and the first appearance of rash and ataxia, and it was felt that this illness and its treatment with sulphonamide over a period of two to three weeks might have interfered with the absorption of vitamins.

The publication by Baron, Dent, Harris, Hart and Jepson (1956) of details of the Hartnup family, and their consideration of two other children described in the British literature as having 'pellagra' seemed to provide an answer to this unresolved diagnostic puzzle. Angela was seen again and a specimen of urine was analysed by Professor C. E. Dent who reported that 'the chromatogram shows a gross disorder of amino-acid excretion, identical with that of our other cases of Hartnup disease'

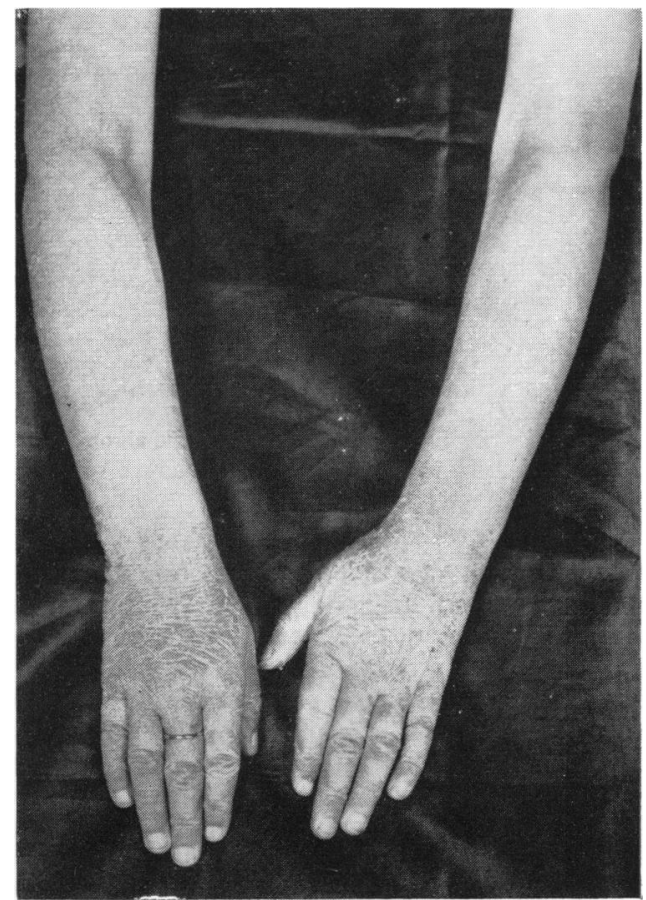

Fig. 1.-The skin lesions (September 1, 1952) 
(Fig. 2). 'Indole chromatograms were also carried out (by Dr. Jepson) and showed the usual gross excretion of tryptophan, indican, indolylacetic acid and indolylacetylglutamine in the pattern characteristic of the disease.'
A detailed investigation of the genetic background in this case has been undertaken and a family tree constructed (Fig. 3).

Angela's father died suddenly in 1955 at the age of 44 from a coronary thrombosis. The paternal grandfather

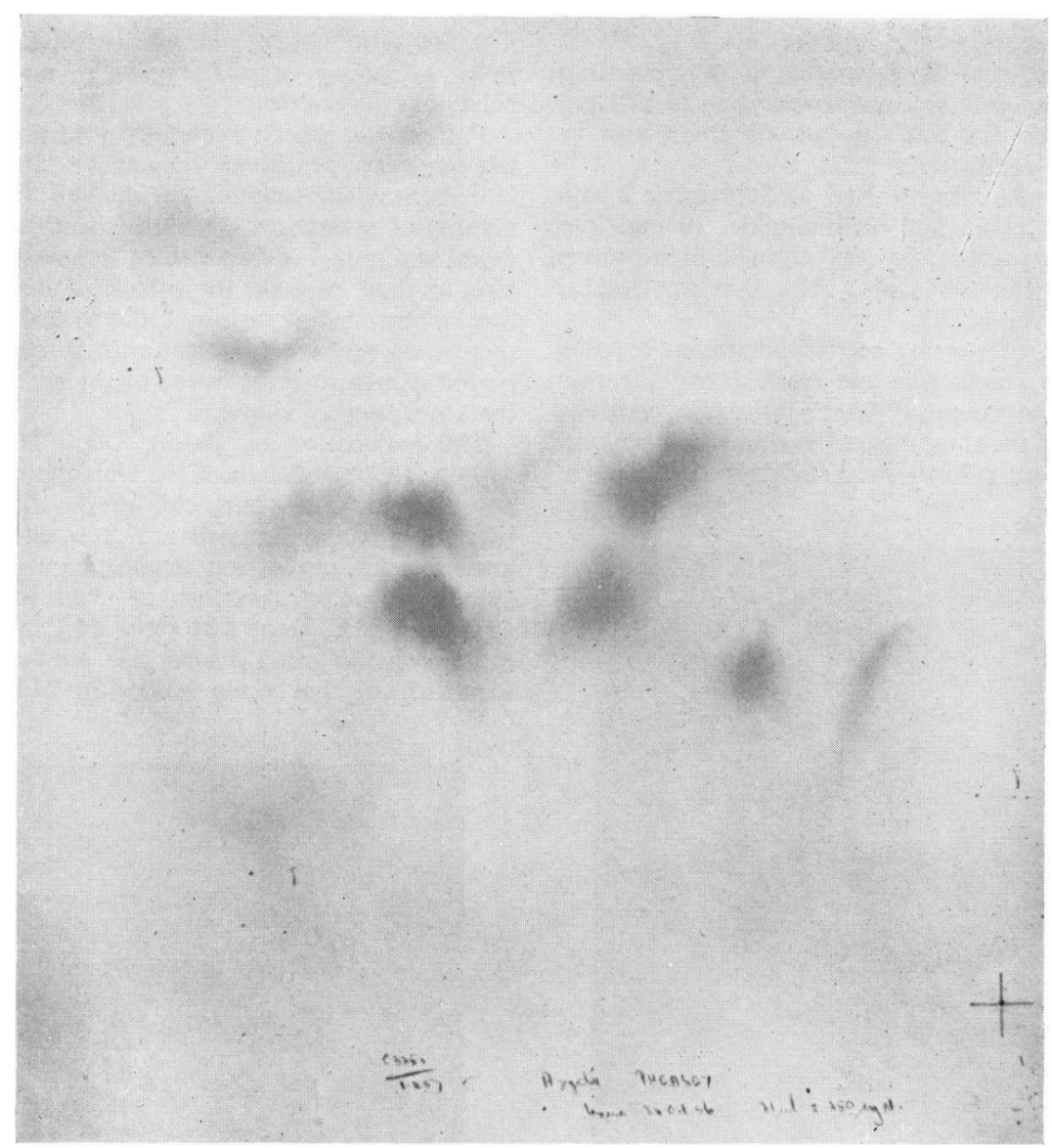

FIG. 2.-Urinary amino-acid chromatogram showing the typical pattern of amino-acid excretion.

At this time, it was noted that she was fit and well, and normally grown for her age. Her I.Q. has not been tested but she shows no evidence of slow mental development. In the intervening three years she had shown no further ataxia and clinical examination of the central nervous system showed no abnormal signs. Her skin, however, continued to show mild sensitivity to sunlight: the backs of the neck and hands readily became reddened and thereafter soon became sore if not treated with calamine lotion. In summer she has to be careful not to expose herself too much in the sun. She has been given no more nicotinamide. died at about 70 , and the paternal grandmother at 78 . The cause of death is not recorded in either case. The maternal grandfather died at 74 of a coronary thrombosis, and the maternal grandmother at 63 of asthma and bronchitis. One of Mrs. P.'s sisters died at the age of 4 years, and a niece died at the age of 9 months, but in neither case is the cause of death recorded.

The urines of 26 of the 31 living relatives (including aunts and uncles and their offspring) have been tested by $\mathrm{Dr}$. H. Harris for amino-acids but none shows the characteristic chromatogram of Hartnup disease. 


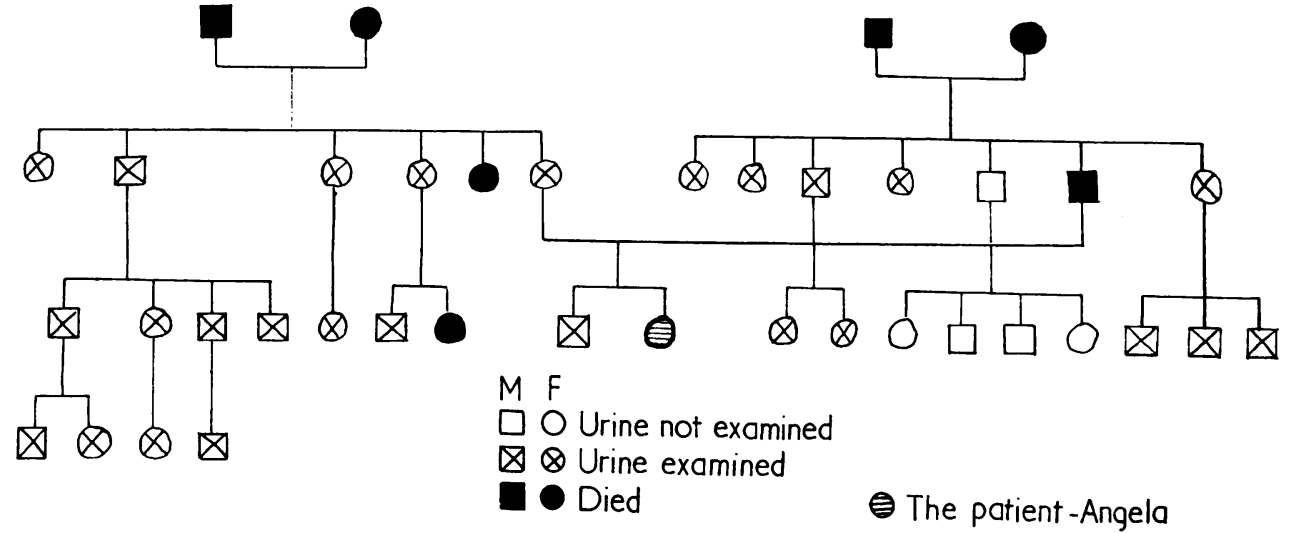

FIG. 3.-The family tree.

\section{Summary}

A case of 'pellagra' in an English child of $4 \frac{1}{2}$ years is described. There was a very satisfactory clinical response to large oral doses of riboflavine and nicotinamide and recovery appeared to be almost complete.

Subsequent investigation at the age of $9 \frac{1}{2}$ years has shown the cause to be the characteristic renal amino-aciduria and other biochemical disturbances associated with Hartnup disease.
I am very grateful to Dr. P. R. Evans for his help in the early stages of this case and to the Department of Medical Illustration, The Hospital for Sick Children, Great Ormond Street, for the clinical photographs; to Professor Dent for his help and encouragement and for permission to reproduce the chromatogram; and to Dr. H. Harris for the family tree.

\section{REFERENCES}

Baron D. N., Dent, C. E., Harris, H., Hart, E. W. and Jepson J. B. (1956). Lancet, 2, 421.

Harris, H. (1957). Brit. med. Bull., 13, No. 1, p. 26

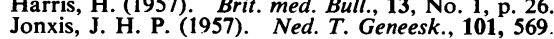

